\title{
Ecos de la Guerra: el exilio antifranquista en la prensa francesa (1944-1953)
}

\author{
Javier CERVERA GIL \\ Universidad Francisco de Vitoria \\ xavicg@yahoo.es
}

Recibido: 13 de enero de 2014

Aceptado: 8 de octubre de 2014

\begin{abstract}
Resumen
Se analiza la posición de la opinión pública francesa ante la causa de los exiliados españoles, numerosos en Francia. Muchos colaboraron en la lucha contra los nazis y ello les granjeó simpatía. Analizamos cómo evolucionó esa opinión los años de teórico aislamiento del Franquismo, hasta 1953. Examinamos las referencias a ese exilio en los seis principales periódicos franceses de estos años. Se concluye que la realidad interna francesa, el contexto internacional y/o el perfil ideológico de cada periódico mediatizan la postura ante ese exilio y el apoyo real de la opinión pública francesa esos años.
\end{abstract}

Palabras clave: Francia; actitud política; prensa; libertades políticas; exiliado; antifranquismo.

\section{Echoes of war: republican exiles in French press (1944-1953)}

\begin{abstract}
This article analyses the stance of French public opinion to the cause of the Spanish exiles present in great numbers in France. Many of them fought alongside the French in the struggle against the Nazis, which earned them considerable goodwill. We analyse the evolution of this opinion throughout the years of theoretical isolation produced by the Franco regime, through to 1953 . We examine the references to the Spanish exile in the six leading French newspapers during those years. The conclusions are that the internal French situation, international events and/or the ideological bias of each newspaper all influence attitudes towards the Spanish exile and the real support of French public opinion at that time.
\end{abstract}

Key words: France; political attitude; press; political freedoms; exile; anti-Franco cause.

\section{Referencia normalizada}

Cervera Gil, J. (2014). Ecos de la Guerra: el exilio antifranquista en la prensa francesa (1944-1953). Historia y Comunicación social. Vol. 19. Páginas 133-152.

Sumario: 1. Consideraciones preliminares. 2. Metodología seguida. 3. Un exilio todavía presente en los medios (1944-1947). 4. La flaca memoria de la prensa francesa. 5. Conclusiones. 6. Fuentes y bibliografía. 6.1 Fuentes primarias. 6.1.1. Archivos: Hemerotecas. 6.1.2. Publicaciones periódicas consultadas. 6.2. Fuentes secundarias. 


\section{Consideraciones preliminares}

A quienes ejecutan el golpe de Estado de julio de 1936 les mueve no tanto un sentimiento antirrepublicano (aunque los había, muchos entre ellos, que también) sino, sobre todo, terminar con aquella República nacida en 1931. No planteaban, en principio, un modelo de Estado (en esto no había un claro acuerdo entre ellos), sino que combatían una legalidad republicana que consideraban hostil a sus ideas y concepción de la vida. Y como aquella legalidad republicana que querían destruir era, entonces, muy afín a la que imperaba al norte de los Pirineos, sabemos que, al principio, había claros deseos en la republicana Francia de ayudar a ese gobierno de Madrid atacado por fuerzas profundamente antidemocráticas y a las que Francia sentía como una amenaza similar a la que entonces crecía desde Berlín. Pero el desarrollo y desenlace de la Guerra Civil fue negativo para la República Española y quienes la defendieron se vieron obligados a huir de lo que, claramente, se había convertido en una guerra de exterminio. Así, se produce un masivo éxodo de los derrotados y el camino que toman tiene como destino Francia, es verdad que condicionado por el discurrir de la ocupación franquista que dejó Cataluña casi para el final, pero también porque esos españoles, que se sienten todos republicanos, aun cuando cada uno en función de su perfil ideológico (comunista, socialista, anarquista, nacionalista...), esperan buena acogida al norte de los Pirineos. Porque no solamente pensaban que el gobierno francés era republicano, sino también que la sociedad sentía mayoritariamente ese republicanismo, y ofrecería su simpatía y buena acogida en suelo galo a quienes habían combatido por la libertad y contra ideas afines a las totalitarias que, al extenderse por Europa, también amenazaban a los franceses.

Así, desde principios de 1939. Francia acoge a decenas de miles de republicanos españoles antifranquistas. La mayoría anónimos, pero, además, intelectuales, dirigentes políticos, diputados, ministros, el Presidente Azaña... dispuestos en los primeros momentos a mantener viva la llama de las instituciones republicanas, que incluso (la Diputación permanente, por ejemplo) se llegarían a reunir antes de que Franco proclamara su victoria, muestra de la esperanza en revertir la situación. Pero la realidad de Francia, a la espera de un conflicto que surgiría 6 meses después, dificultó, si no impidió, la esperada buena acogida a los exiliados republicanos españoles. El resultado para muchos de ellos fue unas muy difíciles condiciones de vida, tanto en los conocidos Campos de la Playa como para los que lograron antes o después salir de ellos.

Y muchos de esos antifranquistas con casi nada que perder terminarían años después por unirse a la resistencia contra la ocupación nazi, plenamente convencidos de que era una continuación a su lucha anterior. No era descabellado pensar que si se conseguía la derrota de Hitler y Mussolini en la guerra europea ello traería, inevitablemente (¡lógicamente!, creían), el final del Franquismo. Su contribución a la Liberación, entusiasta con esa esperanza, generaría, en torno a los años 1944 y 1945, un extendido sentimiento de simpatía en la sociedad gala hacia la causa de esos exiliados. Y, acabada la guerra, también personalidades públicas francesas se 
afanarían por manifestar su rechazo al Franquismo y su solidaridad con esos antifranquistas españoles instalados en Francia.

Por tanto, parece pertinente plantearse si la opinión pública gala y los periódicos que la configuraban mantuvieron esa simpatía hacía una causa en principio afín, cual era la defensa de la libertad, ahora también para España.

Pero Francia padecería una realidad interna de posguerra, dura y complicada, e inmersa en un contexto de Guerra Fría que -lo sabemos- animaría una creciente aceptación, por parte de los aliados occidentales, del régimen español la cual culminaría con la firma de los tratados de septiembre de 1953 entre España y los Estados Unidos. Este trabajo analiza, hasta ese año, si la prensa actuó como aglutinante o animador de la causa del exilio español que quería mantener viva la guerra contra Franco en el seno de sociedad francesa o, por el contrario, la fue olvidando acuciada por esos problemas más cercanos a sus lectores.

En la inmediata posguerra, en Francia, la prensa con gran carga ideológica era, destacadamente, la más leída. No obstante, a partir de 1948, esta prensa de partido empezaría a perder lectores. ${ }^{1}$

Por otro lado, Francia padecía severos problemas económicos a los que se unirían no pocos conflictos laborales con los trabajadores, también los de la prensa, y una indefinición del marco jurídico, porque el tan ansiado Estatuto de la Prensa para el buen desarrollo de su actividad nunca fue posible aprobarlo en el periodo objeto de este estudio. $^{2}$

\section{Metodología seguida}

Inmersos en esta realidad, analizamos seis periódicos que responden a los ámbitos ideológicos y/o sociales significativos en Francia.

En la izquierda, L'Humanité del Parti Communiste Français (PCF), y Le Populaire de la Section française de l'Internationale ouvrière (SFIO). En la prensa conservadora, como más relevantes por el número de lectores y la entidad del sector ideológico en el que se enmarcan, analizamos L'Aube, periódico católico del MRP, partido muy importante hasta 1949; Le Rassemblement, publicación del gaullista Rassemblement du Peuple Français (RPF) formación que releva en peso político al MRP cuando este declina, y Le Figaro, diario no adscrito a partido pero que lee buena parte del conservadurismo francés. Y, por último, Le Monde, el gran periódico francés, muy interesado en cuestiones internacionales y prensa de prestigio, que quiere ser una prensa institucional de referencia en la República.

Se han examinado todos los ejemplares de estas cabeceras en los más de nueve años que abarca este trabajo. $\mathrm{Y}$ hacemos un análisis cualitativo y cuantitativo del interés que manifiestan hacia el exilio español en Francia. 
Se distingue si lo publicado figura en primera página, en la primera con continuación en el interior o sólo en el interior del periódico. En cada caso, además, interesa la extensión de la referencia, señal de la importancia que se le otorga a la información: muy poca (unas líneas), poca (un pequeño cuadro), un espacio medio (tres o cuatro párrafos), un tamaño grande en la página (gran titular y extensión destacable) o una referencia de dimensiones muy grandes (grandes titulares y gran parte de la superficie de la página, o toda ella). La combinación en el análisis de la colocación, con la extensión de lo publicado proporciona una visión ajustada de la importancia que se otorga al tema, el exilio español antifranquista.

Esto se acompaña de un análisis general y sectorial. Como hemos registrado todas las informaciones sobre España de esos años, podemos evaluar el interés por la actividad del exilio, desde 1944/45, en el conjunto del interés por lo español.

\section{Un exilio todavía presente en los medios $(1944-1947)^{3}$}

En 1944, tras la Liberación, el sector de la prensa más interesado en la causa del exilio español es el conservador. En ese año (que no es completo), L'Aube informa de dos iniciativas de estos españoles antifranquistas, y Le Figaro recoge una sola información: la aparición pública de dos personalidades del exilio, Miguel Maura y Juan Negrín.

En cambio, la prensa de izquierdas apenas se ocupa del exilio español en 1944. Sólo los lectores de Le Populaire conocen que hay exiliados españoles en Francia. Pero nada publica L'Humanité.

En 1945 tampoco el diario comunista recoge nada del exilio español. En la prensa de izquierdas es, de nuevo, Le Populaire el más interesado: el exilio supone el 33\% de todas las referencias a España ese año.

No obstante, en un análisis cualitativo, ese interés del diario socialista ya no lo parece tanto: casi nunca la referencia aparece en portada sino en la segunda página, en el $70 \%$ de las ocasiones es muy pequeña y en un tercio sólo se trata de unas pocas líneas. Por otro lado, hay un reduccionismo de origen ideológico: Le Populaire se centra excesivamente en informar sobre las personalidades del PSOE o de la UGT, y mucho menos del resto de formaciones del exilio antifranquista. Casi olvida al PCE, por ejemplo, cuya activismo es superior al socialista. Por tanto, el lector pensaría en un protagonismo de los socialistas españoles en el seno del exilio español por encima del real.

L'Humanité ignora al exilio español en 1945.

En cuanto a la prensa conservadora, lo destacable en L'Aube es que, cuando se interesa por el antifranquismo, ignora el que es iniciativa francesa y su interés se centra en la actividad del exilio español. Eso sí, prima la afinidad ideológica con el PNV, aunque siempre con muy escasa relevancia. 
Con respecto a otros sectores del exilio español sólo cabe citar que, el 30 de agosto de 1945, L'Aube informa, pero muy breve, de una iniciativa favorable del Comité Francia-España, es decir, los comunistas.

Tampoco es especialmente favorable al exilio Le Figaro. La mayoría de las ocasiones el periódico se limita a dejar constancia, con escasa relevancia mediante una información un tanto aséptica, de algún acto, aparición pública o declaración de algún dirigente del exilio español. Más interés muestra el vespertino Le Monde hacia el exilio español: casi el 25\% de lo publicado sobre España en 1945 se refiere a este tema. Además, casi una cuarta parte de esas referencias figuran en la primera página, la mayoría en enero por la reunión de las Cortes españolas en México varios días. Estas referencias son en tamaño mediano, y una noticia, la del reconocimiento del gobierno republicano español por México, en grande y primera página, el resto son sólo pocas líneas. En suma, a Le Monde le interesa el gobierno republicano, el socialismo de Negrín y los monárquicos con don Juan a la cabeza, los sectores más moderados o institucionales.

Avanzamos a 1946 y el interés de L'Humanité por el exilio cambia radicalmente: Publica artículos u opiniones firmadas por exiliados contra el régimen español, pero, curiosamente, no hay referencias al PCE, que es, obviamente, el sector ideológico afín a este periódico.

En el caso del socialista Le Populaire son escasos los contenidos antifranquistas en 1946, pero de estos pocos, la gran mayoría son referencias a la actividad del exilio español en sus sectores moderados: informaciones de la actividad de Giral o de su gobierno, la de socialistas españoles como De los Ríos o Prieto, o las del PSOE. La mayor atención se concentra, con mucha diferencia, en febrero por la enfermedad de Largo Caballero y, después, lo relativo a su muerte. Y en marzo, aparecen las peticiones del exilio español para que se cierre la frontera y el apoyo a tal medida una vez que se lleva a efecto. Son dos meses con la mitad de las referencias al exilio moderado de todo el año. Y como en enero también abundan, resulta que en el primer trimestre de este año, el exilio se convierte en la principal información de España en Le Populaire.

Además, casi dos de cada tres alusiones Le Populaire las publica en la primera página, y la mayor parte son medianamente extensas, grandes o muy grandes; por tanto, el diario manifiesta mucho interés. Sólo un tercio de las alusiones el exilio son de escasa extensión y en página interior: la enfermedad de Largo Caballero se limita a pequeños cuadros diarios, pero cuando muere la noticia merece grandes titulares como sus honras y exequias, con adjetivos elogiosos. Pero la mayor relevancia este año para el exilio es un artículo editorial, el 5 de marzo, por la declaración tripartita firmada por los EE.UU., Francia y Gran Bretaña: se apela a los patriotas y liberales españoles para que provoquen la renuncia de Franco, la eliminación de la Falange y la consulta al pueblo sobre qué régimen se desea. Esto suponía apoyar al exilio, eso sí, al moderado, porque Le Populaire ignora al comunista. Y, probablemente por el 
protagonismo de Largo Caballero, esta cabecera publica más del exilio de lo que lo hace este año L'Humanité.

Muchas menos referencias encontramos en la prensa conservadora. En L'Aube, casi todas las referencias a la actividad antifranquista son del exilio (90\%), pero supone sólo poco más del 13\% de todas las alusiones a España del periódico en 1946. Además, ese interés por el exilio se reduce al nacionalismo vasco y al exilio institucional (Giral y el Gobierno Republicano español). Aparte, encontramos una breve nota de la muerte de Largo Caballero. Y el resto del exilio no aparece en L'Aube. No obstante, estas referencias, mayoritariamente, en primeras páginas, aunque siempre en reducida extensión.

A Le Figaro, en 1946, lo que le interesa es el sector moderado del exilio: los monárquicos, el gobierno republicano o los nacionalistas vascos. Se ignora al PCE. Una nota más del claro anticomunismo de este periódico. El 82\% de estas referencias al exilio aparecen entre febrero y mayo, y la mayoría de las veces en primera página, aunque en tamaños reducidos. Y, después, a partir de julio se publican en páginas del interior $\mathrm{y}$ en pequeños recuadros.

En suma, que ni para Le Figaro ni para L'Aube el exilio español despierta mucho interés en 1946. Por tanto, cabe pensar que los lectores conservadores franceses no estarían en absoluto interesados en la causa antifranquista.

En cambio, en Le Monde el exilio es la referencia a lo español más presente en 1946. También ignora a los comunistas y se centra en los sectores moderados: el gobierno, y, menos, los monárquicos o socialistas. Pero la distribución en el año no es equilibrada: el exilio español aparece mucho más en la primera mitad de 1946. Es más, curiosamente, cuando a finales de año se produzca la condena del Franquismo en la ONU, asunto relevante, Le Monde ignora las reacciones del exilio -que ciertamente sí se produjeron- ante este hecho.

Pero en un análisis cualitativo, observamos que casi el 60\% de las informaciones sobre el exilio se publican sólo en páginas interiores y, habitualmente, la extensión de estas es pequeña o muy pequeña, y raramente, en grandes espacios o ampliamente. Eso sí, cuando el exilio español aparece en portada, en la mitad de las ocasiones, encontramos unos titulares y una extensión mediana.

En suma, Le Monde en 1946 se interesa bastante por el exilio en relación con lo que se ocupa de España, bastante más que la prensa conservadora pero muy lejos de los niveles de interés de la prensa de izquierdas.

Los comunistas, el sector más activo del exilio, ${ }^{4}$ son sistemáticamente ignorados por todos los periódicos, excepto L'Humanité que, en 1947, dedica al exilio algo más del $25 \%$ de las referencias a España, y eso que en cuatro meses no se publica ninguna. El mayor número de alusiones se debe a la crisis del gobierno republicano de Giral, el fracaso de Barcia y la elección de Llopis, en febrero, y, en agosto, la dimisión de este y su sustitución por Albornoz. Por tanto, L'Humanité se acuerda del exilio español en 1947 para reflejar su inestabilidad institucional, y, por ello, intensifica su atención 
sobre el comunismo. Además, la información nunca es extensa: no hay para el exilio una primera página, el $60 \%$ de las referencias son medianas y el resto pequeños recuadro.

El peso del exilio español en Le Populaire en 1947 es similar: poco más del 28\% de las referencias a lo español. La diferencia con L'Humanité es que no hay distribución equilibrada: el $42 \%$ de todas las alusiones al exilio se publican en agosto. Las razones son la celebración en Toulouse del Congreso del PSOE, por un lado, y, por otro, la dimisión del gabinete del socialista Rodolfo Llopis. Además el resto de referencias al exilio, se deben a un seguimiento especial de las actividades públicas de Llopis; y se ignora a los no socialistas. Persiste, pues, en Le Populaire, esa visión distorsionada de la realidad del exilio en Francia: sobredimensionado protagonismo socialista.

Y en el ámbito cualitativo, más del $80 \%$ de las alusiones al exilio en Le Populaire en 1947 aparecen en el interior del diario y casi el 60\% sólo merecen una breve referencia.

Pero la realidad es que la prensa conservadora es la que menos interés manifiesta por el exilio español. No obstante, para L'Aube la única actividad antifranquista en Francia es la que genera el exilio español y el ámbito de la actualidad española más habitual. Además, sólo aparecen alusiones en seis meses. Hay asuntos que se repiten: la crisis del gobierno de Giral, sus dificultades, el nombramiento de Llopis, la crisis se este y su sustitución por Albornoz. Pero para L'Aube tienen más interés los monárquicos, Gil Robles o los nacionalistas vascos. Ese desinterés también se refleja en que en tres de cada cuatro ocasiones el exilio sólo merece el interior del diario. Sólo una vez (la dimisión de Giral el 28 de enero) merece grandes titulares y extensión, y el $70 \%$ de las referencias se limitan a un pequeño recuadro o unas líneas. Y pesa demasiado la afinidad ideológica: L'Aube sólo dedica unas líneas a los problemas del gobierno republicano, pero grandes espacios a la actualidad del PNV. Eso es sobredimensionar la importancia del exilio vasco en Francia. Otro asunto de interés es que, en 1947, ya se detecta en L'Aube tibieza o falta de entusiasmo por la causa del exilio.

Similar imagen del exilio tendrían los lectores de Le Figaro en 1947. Ello significa que tampoco ellos conocerían la verdadera entidad del exilio dentro del conjunto del antifranquismo en Francia, y además este diario ignoraría a los sectores más extremos. Y es que Le Figaro tampoco concede mucha relevancia al exilio y, dentro de este, su valoración de la importancia de las cosas es cuestionable. Así, el asalto al Consulado Español en París aparece en la portada el 8 de noviembre, algo que no sucede con las crisis del gobierno republicano exiliado. En cambio, un posible acuerdo entre Prieto y Gil Robles y como después éste visitaría a Bidault en París, sí merece grandes titulares e importante extensión el 23 de octubre.

Otro panorama presenta, Le Monde en 1947 que dedica una de cada cuatro informaciones sobre España a los exiliados y, además, no hay otra oposición a la dictadura española en Francia más que la de origen español republicano. Pero como en otras cabeceras se mantiene el desequilibrio a lo largo del año. El grueso de las referencias al exilio se concentran en agosto: la llegada de Indalecio Prieto a Francia y, sobre 
todo, la crisis y dimisión de Llopis y su sustitución por Albornoz, con mucha mayor relevancia que la crisis del gabinete Giral y la elección de Llopis, en febrero. Y la mayoría de referencias al exilio español figuran en la primera página y en un tamaño mediano o grande. Por supuesto, Le Monde ignora a los comunistas, y sólo interesan los sectores socialistas más moderados y alguna alusión a don Juan

Se observa que, en 1947, los lectores de prensa franceses pensarían que el exilio español antifranquista era fundamentalmente moderado, e ignorarían, a veces totalmente, a ámbitos más extremos como los comunistas. Y únicamente los lectores de izquierdas pensarían que existía un exilio de cierta entidad y activo; los conservadores considerarían el exilio antifranquista, probablemente, irrelevante.

\section{La flaca memoria de la prensa francesa}

En 1948, tres años después de la Liberación de Francia en la que, sobre todo en el sur, los exiliados españoles se habían ganado el aprecio de la mayoría de los franceses, la prensa francesa ya manifiesta claro desinterés por la causa antifranquista. Es más llamativo sin observamos los medios de izquierda.

Aunque L'Humanité se interesa más por el exilio que Le Populaire, el comunista sólo le dedica un $10 \%$ de todas las referencias a España, y, casi exclusivamente, es a los comunistas: PCE, PSUC o JSU. Se publican con cierta relevancia: en primera página o con gran titular o con una gran extensión. Y, aparte de se menciona al gobierno republicano español, los contactos entre Franco y don Juan, en tono censor, o, sin crítica, una exposición en París sobre la España republicana.

Otra idea clara en L'Humanité es que los comunistas son los exiliados más activos, casi los únicos. Así, el 13 de febrero, la reciente reapertura de la frontera pirenaica motiva un artículo de La Pasionaria, centrado en críticas y duros ataques a la dictadura española.

Y Le Populaire en 1948 centra sus referencias al exilio español en el ámbito socialista. Se da muchísima relevancia al acercamiento entre socialistas y monárquicos en octubre, se dice que para desalojar del poder a Franco.

Sólo en contadas ocasiones Le Populaire, en 1948, informa de otros sectores del exilio (algo que apenas ocurría en 1947). El 16 de junio se ocupa con interés de una exposición de dibujos y carteles de la Guerra de España organizada por el Movimiento Libertario Español (MLE) en el Teatro Lancry de París. Hay alguna referencia al gobierno de Albornoz. Pero es llamativo que ignore totalmente a los comunistas españoles. Por tanto, de nuevo, los lectores de Le Populaire pensarían, equivocadamente, que los socialistas españoles lideraban el exilio, lo cual era falso.

Eso sí, es mayor el desinterés por el exilio en la prensa conservadora. 
El MRP, partido de referencia de L'Aube renuncia en 1948 a cualquier posicionamiento antifranquista, ${ }^{5}$ por lo que es llamativo que el exilio sea el asunto español más presente en el diario y tratado con más relevancia que cualquier otro. Eso sí, como el único que se menciona es el exilio moderado, al final los lectores de L'Aube pensarían que el Franquismo no contaba con una gran oposición.

Así, lo más destacable de la presencia del exilio en L'Aube en 1948 son unos artículos de José Fontbernat, "diputado de la Generalitat de Cataluña", aparecidos en agosto. En ellos se explica cómo fue el acceso de Franco al poder, plantea como "una solución: el federalismo", se analiza "la República española en el exilio" y, el último, aporta unas "visiones de futuro", hacia dónde va España.

Aparte de esto, siempre en páginas interiores y con mediana relevancia, $L$ 'Aube se interesa por el exilio español más afín: el PNV. En un caso, se informa de los monárquicos de don Juan de forma destacada, y de la actividad de Prieto o la detención de Líster, en diciembre, en pequeños recuadros y para manifestar un anticomunismo clásico de este diario.

Y en 1948 aparece otra cabecera conservadora: Le Rassemblement. Es un semanario, fiel portavoz del gaullismo, para el que los exiliados españoles prácticamente no existen: sólo dos alusiones en 1948 y ninguna más hasta 1953.

Esas dos alusiones sirven para canalizar el marcado antisovietismo de Le Rassemblement. El 17 de abril reproduce un manifiesto del MLE en Londres que denuncia el abandono, en las cárceles soviéticas, "de aviadores españoles antifascistas" que fueron entrenarse a la URSS durante Guerra Civil y desde el pacto germano-soviético de 1939 sufren penalidades.

A Le Rassemblement el exilio le es útil para atacar a la URSS. El 23 de julio a toda página y bajo el titular "Los republicanos españoles mueren en los campos de concentración soviéticos", denuncia que el comunista André Marty ignora la suerte de un español preso en la URSS para el que su hermano, exiliado en Francia, había solicitado ayuda.

Y no hay más, luego para el creciente número de franceses gaullistas, los exiliados españoles no existirían. Y recuérdese que el RPF, desde 1948, acrecentaría su peso en la política francesa.

Le Figaro tampoco muestra mucho interés por el exilio español en 1948. Sólo seis alusiones y centradas en lo más moderado del antifranquismo, los monárquicos. De esta forma este diario expresa que el exilio es tan débil que recurre al acercamiento al Franquismo. Los socialistas únicamente aparecen cuando se informa del acercamiento entre Prieto y Gil Robles, con grandes titulares en página interior, los días 8 y 9 de octubre. Y los comunistas sólo para ser censurados cuando se informa, el 24 de diciembre, de la detención de Líster en París y se destaca que es tratado como un delincuente. Por supuesto, a los anarquistas se les ignora. 
La presencia del exilio en Le Monde en 1948 es similar a Le Figaro, con la diferencia de que el vespertino le concede mayor relevancia cuando aparece: un tercio de las informaciones figuran en portada. Se trata de dos declaraciones de Albornoz (en enero y octubre) y el acercamiento de Prieto a los monárquicos (en octubre). Por tanto, a Le Monde le interesa poco el exilio, pero en ese poco, más el institucional (Albornoz) y, en menor medida, el moderado socialista.

Y es tal el desprecio hacia los más activos del exilio, los comunistas, que Le Monde ignora la detención de Líster y sólo se refiere a ellos para recoger que "La Pasionaria está enferma" ( 3 de diciembre). Y, en este último caso, se siente obligado a explicar en su información quién es Dolores Ibarruri, probablemente consciente del escaso interés por el personaje de sus lectores.

En suma, en 1948, ya en Guerra Fría, ese exilio español que aspira a derribar el claramente anticomunista Franquismo, cada vez cuenta con menos eco en los medios franceses, salvo en el caso de la prensa comunista. Pero, incluso en L'Humanité el exilio ya aparece menos.

Ya en 1949, como L'Humanité ignora a los no comunistas, el exilio reduce a un tercio su presencia en este diario con respecto a 1948. Pero ya sólo es esta cabecera la que habla de los exiliados comunistas españoles en Francia, pocas veces, pero eso sí con gran relevancia. Se trata de artículos o manifestaciones de líderes como La Pasionaria en noviembre y diciembre o actos públicos de los comunistas españoles como un mitin el 12 de julio en la Sala Wagram de París ampliamente aludido varios días. Pero no hay más exilio español para L'Humanité.

Y es Le Populaire el que más interés dispensa al exilio español en 1949 y con mayor relevancia. Curiosamente lo más destacada es el 18 de noviembre cuando "La Pasionaria arrestada por titismo" en Praga. Es el antiestalinismo del diario. Pero ya incluso el exilio socialista pierde peso en favor del gobierno republicano español al que se le concede mayor relevancia tipográfica. El desinterés por el PSOE se debe a que el socialismo español continúa dividido y no se pronuncia con una sola voz, lo que hace complicado elegir una facción y además merma la actividad antifranquista de los socialistas españoles.

Y si el exilio en 1949 pierde peso en la prensa de izquierdas, mucho más en la conservadora. Un primer dato: este año Le Figaro no menciona ni una vez al exilio. Y L'Aube sólo publica tres breves referencias de escasa relevancia.

La primera, informa de la remodelación del gobierno republicano el 17 de febrero. El 19 de abril da cuenta de la "celebración en París del aniversario de la proclamación de la República Española”, cinco días después de la efemérides y a pesar de que al acto asistieron tres ministros franceses. Y la tercera es incluso discutible que sea una alusión al exilio, y además no se produce en Francia: el 19 de noviembre llega el velero "María del Pino" a Brasil y sus ocupantes declaran que vienen huidos de España. Eso es todo. 
Si la prensa refleja las preocupaciones de la opinión pública, cabe pensar que los franceses conservadores en 1949 han perdido casi todo el interés por el exilio antifranquista en su tierra.

Tampoco Le Monde presta mucha atención a los exiliados y las pocas veces que lo hace se interesa por el moderado institucional republicano. En febrero se informa de la muerte en Buenos Aires de Niceto Alcalá Zamora, y se cita, pero no se valora, la renovación del gobierno republicano exiliado. Y ya el 12 de noviembre una brevísima referencia a unas declaraciones en México del socialista Álvarez del Vayo: "España no podrá formar parte del Pacto Atlántico". También los lectores del vespertino habrían perdido su interés por la causa del exilio.

Esta tendencia se acentúa en los comienzos de los cincuenta en que las apariciones del exilio en prensa son cada vez más episódicas y menos constantes. Además, un hecho, la Operación Bolero Páprika organizada por el gobierno francés contra el comunismo, fundamentalmente español, en septiembre de 1950 provoca un tinte negativo o censor a las informaciones sobre el exilio. ${ }^{6}$ Por ello, L'Humanité trata de ignorar este episodio y se centra, especialmente, en la protesta y solidaridad del PCF con el PCE. Antes de la operación policial citada se ocupa, y no mucho, de la actividad de los comunistas españoles, en especial de "La Pasionaria", o dos mítines que tienen lugar en París, en abril y junio de 1950.

Y cuando se produce la acción policial, el 8 de septiembre, L'Humanité coloca en portada y grandísimos titulares: "Con desprecio del derecho de asilo; cerca de 300 arrestos de antifranquistas españoles y de demócratas inmigrantes" y compara a la policía francesa con la GESTAPO nazi durante la ocupación. Pero sorprende que el diario conceda poco espacio al PCE para que se defienda: simplemente el 15 de septiembre publica, con gran relevancia, eso sí, un telegrama de "La Pasionaria", enviado desde Moscú, en el que protesta por la Operación Bolero-Paprika. El resto de protestas publicadas proceden del PCF, no de los comunistas españoles.

Pero después de estos hechos L'Humanité baja el tono. La presencia del exilio español en sus páginas se limita a un pequeño anuncio de la venta de Fiere Espagne de Constancia de la Mora, la felicitación, el 11 de diciembre, a "La Pasionaria" por su cumpleaños o, el 27 de diciembre, el mensaje emitido por "Radio España Independiente", del Comité Central del PCE contra la decisión de la ONU de levantar las sanciones contra España.

En Le Populaire, aunque en 1950 reduce su interés por España, el exilio es lo que más aparece del ámbito español y además con gran relevancia: el 25\% de las referencias figuran en primera página, y casi siempre con grandes titulares y apreciable extensión. Pero cuando desde septiembre informa -sin opinar- de la Operación Bolero-Paprika tiñe sus informaciones sobre el exilio de anticomunismo. Y para ello, encuentra terreno propicio en la citada acción policial que enmarca en "la lucha contra las quintas columnas" de comunistas en Francia y ataca con saña al PCE. Y dos meses después ofrece sus páginas a Valentín González, "El Campesino", para que desde el 14 de noviembre al 21 de diciembre firme unos artículos en que, además de atacar al Franquismo, se despache a gusto contra los comunistas. Esto minimiza 
la referencia en noviembre a las reacciones del gobierno republicano español a la resolución favorable a la España franquista de la ONU.

No hay más en la izquierda.

$\mathrm{Y}$ en la prensa conservadora es llamativo que el católico y tan anticomunista, L'Aube ignora totalmente la Operación Bolero Páprika, ni para celebrarla. En 1950 la única alusión al exilio antifranquista es la noticia de un telegrama de los republicanos españoles al Sr. Trygve Lie en que critican la ya citada resolución de la ONU favorable al Franquismo por ser un "increíble esfuerzo por consolidar el fascismo en España."

En cambio, Le Figaro sí presta más atención al exilio porque sí concede mucho espacio a la Operación Bolero Paprika que le sirve para dar salida a su anticomunismo y criticar a la URSS. Con la alusión a la citada operación el diario aprovecha para atacar al exilio español que considera dominado por los comunistas. El 8 de septiembre publica: "En París, en el norte, el suroeste y el sureste. Vasta operación de policía contra las quintas columnas establecidas en Francia por los partidos comunistas extranjeros. Más de 200 indeseables han sido detenidos y la mayor parte inmediatamente expulsados". Y al día siguiente, en portada: "266 indeseables han sido detenidos o puestos en residencia vigilada". Este diario sí se felicita por la actuación contra los comunistas españoles. Además, destaca las declaraciones del Gobierno Republicano español en las que se desmarca y desautoriza o critica a los comunistas. También Le Figaro ofrece un hueco a "El Campesino" en octubre para que durante tres días ataque a la URSS por cómo se cobró su ayuda durante la Guerra Civil a los comunistas que luego se refugiarían en Francia. En suma, para este diario, el exilio español es ya sólo el medio para atacar al comunismo.

Le Monde en 1950 actúa de forma muy similar: la Operación Bolero-Páprika de septiembre es una ocasión para elevar el tono censor y negativo contra los comunistas exiliados españoles. Esos días de septiembre el vespertino informa ampliamente y con alegría del episodio y el 12 recoge la nota del gobierno republicano español que lo celebra.

Pero al margen de la operación de septiembre, ya en enero, Le Monde había dado espacio a exiliados españoles que en extensos artículos contra el Franquismo también censuraban severamente a los comunistas. El resto de alusiones al exilio en 1950 son breves notas sobre la audiencia del Papa a don Juan (marzo), el mensaje en la efemérides de la II República de Martínez barrio (abril), unas breves declaraciones de Líster contra Franco (abril) y la vuelta de Albornoz como jefe de gobierno republicano (diciembre). En suma, a Le Monde el exilio le sirve para atacar al comunismo fundamentalmente; el resto son informaciones de su (escasa) actividad y sin posicionarse.

Pero claro, el ataque al comunismo español, lo más activo del exilio, en la operación de septiembre de 1950 deja muy tocada la causa antifranquista en Francia. Y a partir de entonces, el exilio pierde progresivamente aún más presencia mediática. 
Esto se nota mucho en L'Humanité que desde 1951 se va olvidando de sus camaradas españoles. Sólo tres presencias este año: en enero y en julio dos artículos, eso sí con relevancia tipográfica, de La Pasionaria, pero que ya había publicado en Pravda fechas antes. Y, el 27 de julio, unas declaraciones de José Giral contra la visita del Almirante Sherman a España con el objeto de negociar una alianza militar de los estadounidenses con Franco. Y no hay más.

Más interés por el exilio en 1951 muestra Le Populaire que además coloca la mitad de sus alusiones en portada y de forma bastante relevante. Ello hace que referido a España, lo que más leyeran los socialistas franceses serían referencias al exilio. Pero como venía siendo habitual este diario traslada una imagen del exilio que no se ajusta demasiado a la realidad. Porque el mayor número de referencias y con mayor relevancia es a los socialistas lo que los colocaba como los más comprometidos con el antifranquismo, lo cual no era verdad. Y Le Populaire ignoraba casi por completo a los más activos, los comunistas: Una sola alusión de pocas líneas el 8/9 de diciembre para "La Pasionaria" que está en Berlín Este para la reunión de Federación Internacional Democrática comunistas. Es un reflejo irreal del exilio en Francia.

Y en 1951 L'Aube sólo sale diez meses hasta su desaparición. Y en ese proceso de extinción encontramos sólo cinco referencias al exilio, siempre el moderado. El 16 de abril resumen del manifiesto de Diego Martínez Barrio por el vigésimo aniversario de la República Española. En mayo, de nuevo, la sobrevaloración del nacionalismo vasco: dos apariciones de José Antonio de Aguirre, en una entrevista y en declaraciones contra la represión de las huelgas en Vizcaya. Una breve nota el 18 de julio informa de la dimisión de Álvaro de Albornoz. Y, por último, el 22 de julio, unas declaraciones de don Juan en que llama "totalitario y nazi" a Franco.

Y ese espacio mediático que abandona el MRP y L'Aube lo ocupa el gaullismo y Le Rassemblement. Pero este semanario ignora totalmente al exilio. Es decir, para el creciente número de franceses gaullistas, el exilio español no existiría.

A ello se une que el conservador Le Figaro, en 1951, únicamente alude al exilio el 21/22 de julio: un pequeño recuadro en página interior con declaraciones de don Juan de Borbón. Es, pues, algo testimonial e irrelevante.

Le Monde no muestra mayor interés este año. Escasas referencias, siempre en pocas líneas, en página interior y a sectores moderados del exilio. Una nota sobre la expulsión de Liga Mundial de Amigos de los Vascos de su sede parisina en la Avenida Marceau que pasa a manos de la Embajada de España, las críticas de don Juan al nuevo gobierno franquista y un par de alusiones al gobierno republicano en el exilio por el 14 de abril o por la formación del nuevo gabinete de Gordón Ordax. Y no hay más en 1951.

El año siguiente se acentúa el olvido del exilio. L'Humanité continúa ignorando todo lo que no sea el PCE pero también escasea su presencia y merma su relevancia tipográfica. Una nota de condolencia el 23 de abril del Comité Central del PCE por la muerte de Pierre Rouquès, ${ }^{7}$ y, el 6 de junio, la solicitud de libertad para el comunista 
Jacques Duclos que hace el PCE. Es, más bien, solidaridad con los camaradas franceses que actividad antifranquista. Ya ni siquiera el diario comunista considera al PCE un elemento activo contra el Franquismo.

Ello supone que, en 1952, es Le Populaire el más interesado en el exilio español. Porque, por ejemplo, se acuerda del ingreso de España en la UNESCO y le concede espacio dos días en abril y otro en junio al socialista Rodolfo Llopis para que censure esta decisión que considera inaceptable. Esta crítica a la UNESCO es lo más relevante de la presencia del exilio en Le Populaire. El resto son brevísimas alusiones al PCE, en enero, porque decide marcar distancias con la URSS, a una distinción que recibe Pablo Casals de la República Española, y unas líneas para el recuerdo de Martínez Barrio al $79^{\circ}$ aniversario de la Primera República española.

Y como la prensa conservadora ignora totalmente al exilio en 1952, hemos de pasar a Le Monde que sólo hace cuatro referencias este año y centradas en el antifranquismo moderado, con críticas al PCE. También se acuerda el 12 de febrero de la Primera República Española a través de las palabras de Martínez Barrio y también trae a escena a Llopis en abril por su escrito contra el Franquismo en la Conferencia Internacional Socialista de Londres. Una breve alusión a don Juan que designa al Conde de Los Andes como representante exterior. Y el 19 de diciembre, el vespertino ataca al PCE por querer capitalizar las huelgas de Barcelona que en realidad protagonizan anarquistas y catalanistas.

Y alcanzamos el último año de nuestro estudio, 1953, sin mucha novedad: sólo los lectores de izquierda tendrían noticia de existencia de exiliados antifranquistas en Francia.

L'Humanité en su línea: sólo existía el PCE. Se le concede un recuadro pequeño para que el 7 de marzo exprese su pesar por la muerte de Stalin como -se autotitulaportavoz "de las masas populares de España". Lo llamativo es que el diario hace, durante días, gran despliegue por la muerte del tirano pero unas pocas líneas es el único espacio que se concede al comunismo español en este contexto. El desinterés por el exilio es manifiesto y el diario comunista elige que sea la cultura española la imagen del exilio: el 25 de marzo, en portada, Picasso se opone a los acuerdos Bonn-París y, un mes después, el mismo pintor "visita a Maurice Thorez". Pero este diario tarda dos semanas en recoger una crítica a los acuerdos hispano-americanos de septiembre, y la hace el socialista Indalecio Prieto.

El exilio más activo es el comunista, pero es el socialista Le Populaire el más interesado por los antifranquistas, tanto en número de alusiones como en la relevancia de estas: casi siempre con grandes titulares y gran extensión, aunque en interior del diario. El problema persiste en que sobredimensiona el peso del socialismo y del gobierno republicano en el exilio. Referencias en febrero a posicionamientos del PSOE y de la UGT sobre la mala situación sindical en España o, en septiembre, un manifiesto de ambas formaciones "Contra la firma de los acuerdos hispano-americanos". Y del gobierno del exilio recoge otra manifestación de oposición a esos tratados, pero previa, en mayo, tanto del gabinete como de su presidente Julio Just. 
Después, el 1 de octubre publica el comunicado de protesta del gobierno del exilio contra esos tratados.

Al margen de los famosos acuerdos, Le Populaire concede amplio espacio al exiliado Víctor Alba para que, con el pretexto de comentar el libro Yo fui ministro de Stalin de Jesús Hernández, critique la intervención de la URSS en la Guerra de España porque lo considera la causa de todos los problemas que padece el exilio. Y en la misma línea, el 22 de abril, el diario informa de que "después de 'El Campesino', Jesús Hernández se escapa de Rusia". El comunismo español vuelve al centro de las críticas.

Y, como la prensa conservadora ignora al exilio en 1953, sólo resta mencionar a Le Monde... y sin excesos. Dos alusiones: en abril que "Don Juan no renunciará a los derechos al trono" y una mínima alusión, en noviembre, al V Congreso de la UGT en el exilio en Toulouse. En suma, también escasísimo interés de Le Monde por la realidad del exilio en Francia.

\section{Conclusiones}

Una primera consideración es que la evolución de las posiciones de la prensa francesa discurre paralela a la de la propia sociedad francesa. Los medios se olvidan, progresivamente, de los republicanos españoles, muy queridos al principio por su ayuda en la Liberación de Francia. Esto es antes y más relevante en la prensa conservadora, pero, con una matizada excepción en el caso de L'Humanité, y sólo para el exilio comunista, también sucede en la de izquierdas.

Sin duda alguna "L'Humanité" fue el periódico francés más intensamente antifranquista en los años de la posguerra. En esto no hacía más que seguir la línea del partido del que era portavoz, al que incluso daba indicaciones. Pero la realidad fue que ese mayor interés por el exilio, poco a poco se iría concentrando exclusivamente en el PCE. Y acabaría excluir al resto del exilio, en un contexto de un comunismo pleno de antiamericanismo. Y cuando esto empieza a perder sentido, "L'Humanité" opta por los opositores a la Dictadura dentro de España y se aleja del exilio.

La prensa socialista muestra cierto interés por el exilio al principio pero, su excesiva atención a un socialismo español, con palpables y crecientes disensiones y divisiones internas, y que la irrupción de la Guerra Fría tiñó su antifranquismo de una visión antisoviética le condujo a centrarse exclusivamente en atacar al PCE. Ello terminaría por trasladar la imagen, falsa, de que el sector más activamente antifranquista del exilio español eran los socialistas.

En la prensa conservadora, L'Aube, debido a su posición muy anticomunista, conforme se incrementa el protagonismo del PCE en el exilio español, se olvida de esos exiliados porque los identifica casi exclusivamente con comunistas. Cita también a los socialistas, pero sólo por su presencia en el gobierno republicano en el exilio. El 
mayor interés lo dispensa entonces a la facción más afín ideológicamente: el nacionalismo vasco. Esto distorsiona la realidad porque dedica una atención excesiva al PNV en relación con su real importancia en el conjunto del exilio. Además se promociona la unión de los demócratas españoles, pero como excluye a los comunistas (a los anarquistas ni se los plantean) se inclina por esos sectores moderados del exilio. Y al no ser esto viable o posible, acaba por aceptar el gobierno vigente en Madrid como mal menor.

Y es llamativo que casi nula es la preocupación por la causa del antifranquismo español en el semanario gaullista Le Rassemblement: apenas existe y cuando se hace referencia a ello es para atacar la existencia y actuaciones de los más activos, los hombres del PCE. Esa indiferencia hacia lo español en estos años concuerda con las actitudes y posiciones de De Gaulle.

Dentro del ámbito conservador, Le Figaro, que no se vincula a ningún partido, es el diario conservador menos preocupado por el exilio desde 1944. Es más, con el paso de los años, acentúa su crítica a estos españoles antifranquistas porque los ve como una alternativa peligrosa - por el protagonismo comunista- al régimen español. Con lo cual, como había hecho L'Aube -aunque este desaparece en 1951-, aplica aquello de que más vale el mal menor y acaba por manifestar tolerancia hacia el Franquismo, $\mathrm{y}$, consiguientemente, el casi total olvido de la causa del exilio.

Y, para terminar, hasta un diario de prestigio como Le Monde, si bien al principio se interesa mucho por la causa antifranquista, con el paso de pocos años, se da cuenta de la inviabilidad del exilio como alternativa consistente al régimen franquista. Aún en 1947, atiende la actualidad del exilio, pero el institucional u oficial moderado como la única alternativa aceptable al régimen imperante en España contra la posibilidad peligrosa de que al Franquismo le sustituyera un régimen con protagonismo comunista. No obstante, quizá porque se iba viendo que ese exilio institucional u oficial no era viable como alternativa, en los cincuenta, en la línea de muchos franceses, Le Monde ya considera que, de momento, con el Franquismo, aunque sea inaceptable como sistema y régimen, es con el estado español con el que hay que convivir. Lógicamente, esto conduce al vespertino a reducir considerablemente su interés por los exiliados en Francia.

En suma, una conclusión final: la causa del exilio español fue apoyada con entusiasmo por la opinión pública francesa en general sólo al principio de la posguerra, cuando Franco era tan despreciado como los tiranos recién derrotados. Pero, cuando aparecieron problemas graves en el entorno inmediato, a los franceses les preocupó más resolverlos y salir adelante en su vida ordinaria antes que ocuparse de asuntos que, al fin y al cabo, derivaban de una realidad extranjera. $Y$ en los primeros cincuenta, en el conjunto de la prensa francesa, salvo L'Humanité -y levemente y de forma muy sectaria-, el exilio español antifranquista ha perdido de forma muy clara la batalla mediática, al igual que el aprecio de la sociedad francesa. Para su desgracia, no era el único ámbito en el que la causa antifranquista, en general, y el exilio espa- 
ñol, en particular, ya no interesaba casi nada en Francia. Tampoco importaba mucho en el ámbito de la política francesa, en el internacional, en el ámbito cultural, etc...

\section{Fuentes y bibliografía}

6.1 Fuentes primarias

\subsubsection{Archivos: Hemerotecas}

Bibliotèque Historique de la Ville de Paris (BHVP). Fondo de Periódicos. París (Francia)

Bibliotheque de Documentation Internationale Contemporaine en la Université de Nanterre (BDIC). Section periodiques. Nanterre (Francia).

Hemeroteca Nacional en la Biblioteca Nacional de España (BNE) en Madrid (España).

\subsubsection{Publicaciones periódicas consultadas}

L’Aube. París; 1944-1953.

Le Figaro. París; 1944-1953.

L'Humanité. París; 1944-1953.

Le Monde. París; 1944-1953.

Le Populaire. París; 1944-1953.

Le Rassemblement. París; 1948-1953.

\subsection{Fuentes secundarias}

AGUDO “BLANCO”, Sixto. (2003) Los españoles en la resistencia francesa y su aportación a la lucha antifranquista. Zaragoza; Unaluna Ediciones (Colección Amarcord, $n^{\circ}$ 5).

ANGOUSTURES, Aline. (1987) L'opinión publique française et l'Espagne. 19451975. Tesis para el doctorado del Instituto de Estudios políticos de París, bajo la dirección del profesor Pierre Milza. París.

(1996)“Les refugies européens au coeur du statut de refugies"; en Matériaux pour l'histoire de notre temps; n 44; octubre-diciembre 1996 (pp. 66 a 71).

ARMINGOL, Martín. (1995) Mémoires d'un exilé espagnol insoumis. 1931-1992. París; L'Harmattan.

AZCÁRATE,Pablo de, y VIÑAS, Ángel (ed.) (2010) En defensa de la República: con Negrín en el exilio. Barcelona; Crítica.

BACHOUD, Andrée y DREYFUS-ARMAND, Geneviève. (1994) "Des espagnols aussi divers que nombreux, Paris 1945-1975" en Le Paris des étrangers depuis 1945, dirigido por Antoine Marès y Pierre Milza. 
BARRILLON, R.(1995).'Le RPF”, en Partis politiques et classes sociales. París.

BARTOLÍ, Josep. (2009). La retirada: exode et exil des républicains d'Espagne. Arles; Editions Actes Sud, collection Actes Sud BD.

BELLANGER, Claude; GODECHOT, Jacques; GUIRAL, Pierre, y TERROU, Fernaud. (1975) Histoire Genérale de la Presse Française. "Tomo IV: De 1940 à 1958". París; Presse Universitaires de France.

BERTAZIOLI RIQUER, Fernando. (1996) Memorias de la guerra y del exilio. (Memorias de mi infancia en Ibiza durante la Guerra Civil y del exilio posterior). Ibiza; Editorial Mediterrània.

CARLÉS, Marcial. (1997) "Entre la “Guerra Fría” y el "deshielo" poststaliniano. Aproximación a la política internacional del P.C.E." Comunicación en TUSELL, Javier; AVILÉS, Juan; PARDO, Rosa; CASANOVA, Marina; MATEOS, Abdón; SEPÚLVEDA, Isidro, y SOTO, Álvaro (Editores); La política exterior de España en el siglo $x x$ (actas de congreso); Madrid; UNED.

CATALA, Michel. "Les politiques françaises vis-a-vis de l'Espagne. Raprochement nécessaire, réconciliation imposible. Janvier 1939-août 1944"; tesis doctoral dirigida por el professor Yves-Henri Mouailhat, de la Universidad de Nantes; 1995. Resumen publicado en Imaginaires et symboliques dans l'Espagne du franquisme; Bulletin d'Histoire Contemporaine de l'Espagne; no 24; diciembre de 1996. Centre National de la Recherque Scientifique (CNRS) Maison des Pays Ibériques. Burdeos.

CENTRE D'HISTOIRE DE L'EUROPE DU VINGTIÈME SIECLE. (1999) Enfants de la guerra civile espagnole. Vécus et représentations de la génération née entre 1925 et 1940. París; L'Harmattan.

CERVERA GIL, Javier. (2007) La Guerra no ha terminado. El exilio español en Francia, 1944-1953. Madrid: TAURUS.

CUESTA, Josefina y BERMEJO, Benito (coord.) (1996) Emigración y exilio. Españoles en Francia. 1936-1946. Madrid; EUDEMA.

CHARLOT, Jean. (1983) Le gaullisme d'opposition 1946-1958. Histoire du gaullisme. París; Fayard.

DE GAUlLE, Charles. (1970) Discours et messages. Tome X: Pendant la guerre (1940-1946). París; Librairie Plon.

(1970) Discours et messages. Tome XI: Dans l'attente (1946-1958). París; Librairie Plon.

DREYFUS, François-G. (1982). De Gaulle et le gaullisme. París; PUF; 1982.

DREYFUS-ARMAND, Geneviève (1998). "Daniel Mayer et les républicains espagnols"; en Matériaux pour l'histoire de notre temps; no 51-52; julio-diciembre 1998 (pp. 70 a 73).

(1999) L'exil des républicains espagnols en France. De la Guerra civile à la mort de Franco. París; Albin Michel.

(1999) "La politique des pouvoirs public français à l'égard des refugies espagnols, 1936-1940" en Les politiques publiques face au problème migratoire; $\mathrm{n}^{\circ} 7$ de la Revista del CERIC (Centre d'Études et de Recherches Inter-Européennes Contemporaines); París; 1999 (pp. 147-164).

DUCLOS, Jacques (1951). Non, le fascisme ne passera pas! París, PCF. 
(1952) Comment combattre et vaincre le fascisme. París, PCF.

DULPHY, Anne. (1984). La politique de la France a l'egard de l'Espagne franquiste, 1945-1949. Memoria de la DEA bajo la dirección del profesor Pierre Milza; París; Cycle Supérieure d'histoire du XX ${ }^{\mathfrak{e}}$ siècle.

(1999)“Un miroir des relations franco-espagnoles: les maquisards FFI-FTP détenus par le régime franquiste 1944-1955" en Les politiques publiques face au problème migratoire; $\mathrm{n}^{\circ} 7$ de la Revista del CERIC (Centre d'Études et de Recherches Inter.-Européennes Contemporaines); París; (pp. 179 a 203).

ELLANGER, Claude; GODECHOT, Jacques; GUIRAL, Pierre, y TERROU, Fernaud. (1975). «La presse de la IV République ». En Histoire Genérale de la Presse Française. Tomo IV: De 1940 à 1958. París: Presse Universitaires de France.

GROSSE, Ernst Ulrich y SEIBOLD, Ernst (dir.). (1994) Panorama de la Presse Parisienne. Frankfurt; Peter Lang.

MARÍN PRAT, Progreso. (2009) Exilés espagnols, la mémoire à vif. Portet-sur-Garonne; Loubatières.

MARTÍN CASAS, Julio y CARVAJAL URQUIJO, Pedro. (2002) El exilio español (1936-1978). Barcelona; Planeta.

MARTY, André (1946). Pour la sécurité de la France. Rupture avec l'Espagne de Franco. Repaire de Nazis, des Miliciens et d'Espions! París; PCF.

MOTTIN, Jean. (1949) Histoire politique de la presse (1944-1949). Paris, Ed. Bilans hebdomadaires.

MUÑOZ ALDAY, Francisca. (2006) Memorias del exilio. Barcelona; Viena.

PURTSCHET, Christian. (1965) Le Rassemblement du Peuple Français 1947-1953. París; Cujas.

RUBIO, Javier. (1997) La emigración de la Guerra Civil de 1936-1939. Historia del éxodo que se produce con el fin de la II República Española. Madrid; Editorial San Martín.

SOO, Scott. (2013) The routes to exile: France and the Spanish Civil War refugees, 1939-2009, Manchester, Manchester University Press, 2013.

STEIN, Louis. (1981) Par-delà l'exil et de la mort: les républicains espagnols en France. Paris; Mazarine.

THIBAU, J. (1978) Le Monde. Histoire d'un journal. Un journal dans l'histoire. París; Simoen; 1978

YUSTA; Mercedes. (2009) Madres coraje contra Franco: la Unión de Mujeres Españolas en Francia, del antifascismo a la Guerra Fría (1941-1950). Madrid; Cátedra; 2009. 


\section{Notas}

1 BELLANGER, Claude et al., "La presse de la IV République". En Histoire Genérale de la Presse Française. Tomo IV: De 1940 à 1958. (París : Presse Universitaires de France, 1975) 273-456. Y, GROSSE, Ernst Ulrich y SEIBOLD, Ernst. Panorama de la Presse Parisienne. Frankfurt: Peter Lang, 1994.

2 MOTTIN, Jean. Histoire politique de la presse (1944-1949). París: Ed. Bilans hebdomadaires, 1949.

3 El análisis y conclusiones del presente trabajo son producto del vaciado de las colecciones completas de las seis cabeceras que se citan. Ha sido necesario trabajar en tres distintas bibliotecas que conservan fondos hemerográficos para lograr completar la totalidad de los ejemplares de los nueve años objeto de estudio de los seis periódicos: la Biblioteca de Documentación Internacional Contemporánea (BDIC) de la Universidad de Nanterre (Francia), la Biblioteca Histórica de la Villa de París (BHVP) en la capital francesa y la Biblioteca Nacional de España (BNE) en Madrid.

4 Se puede constatar en CERVERA GIL, Javier. La Guerra no ha terminado. El exilio español en Francia, 1944-1953. Madrid: TAURUS; 2007.

5 En 1948, el MRP había eliminado de sus preocupaciones la cuestión de la dictadura en España. Véase CERVERA GIL, Javier. Op. Cit (2007): Pp. 376 a 389.

6 Una amplia explicación de esta operación policial contra los comunistas en CERVERA GIL, Javier. Op. Cit. (2007): Pp. 567 y ss.

7 Fundador y abastecedor del servicio sanitario de las Brigadas Internacionales durante la Guerra de España.

\section{El autor}

Javier Cervera Gil es Doctor en Historia Contemporánea y en Ciencias de la Información (ambos por la UCM). Profesor titular de la Universidad Francisco de Vitoria y acreditado como profesor titular por la ANECA. Especialista en la Historia contemporánea y de la comunicación. En el campo de la Guerra Civil Española autor de varias monografías acerca de Madrid, del final del conflicto, la vida cotidiana o, en la actualidad en prensa, sobre la regulación legal de la represión republicana. Y en relación con el exilio republicano en Francia también ha publicado una monografía además de capítulos en libros colectivos. Por otro lado, autor de artículos en revistas de impacto y ponente en congresos en España y en el extranjero. 